\title{
Aplikasi Distribusi Maxwell-Boltzmann dalam \\ Menentukan Kecepatan Molekular
}

\author{
Oleh: Widya Wati, M.Pd ${ }^{1 *}$
}

\begin{abstract}
Abstrak
Distribusi Maxwell-Boltzmann adalah salah satu dari tiga distribusi partikel yang dikenal pada sistem partikel. Distribusi Maxwell-Boltzmann, masih dalam kategori pada sistem partikel klasik, dimana partikel-partikel didalamnya masih dapat terbedakan.Salah satu penerapan distribusi Maxwell-Boltzmann yang ada disekitar kita adalah distribusi partikel pada tabung gas rumahan baik yang $3 \mathrm{~kg}$ maupun $12 \mathrm{~kg}$. Dengan memahamidistribusi Maxwell-Boltzmann, kita dapat mengetahui bagaimana kecepatan molekular yang terjadi pada tabung gas.Pada tulisan ini dipaparkan akan dipaparkan aplikasi distribusi Maxwell-Boltmann dalam menentukan kecepatan molekular, visualisasi ruang kecepatan, kecepatan gas dalam tabung gas, dan juga fenomena ledakan tabung gas.
\end{abstract}

Kata Kunci: Distribusi Maxwell Boltzman, Kecepatan molekular, Tabung gas

\section{Pendahuluan}

Di dalam mekanika statistik, fungsi distribusi $f(E)$ bagisistempartikelidentikmerupakanpeluangsebuahpartikelberadapadatingkatener

gi E.Fungsiinimerupakanperluasangagasanpeluangdiskretuntukkasus yang energinyakontinu,

Sampaisejauhini, di alam, paling tidakterdapattigafungsidistribusi yang berbeda, yaitufungsidistribusi Maxwell-Boltzmann, Bose-Einstein, dan FermiDirac. Fungsidistribusi Maxwell-Boltzmann berlakuuntukpartikelidentiktetapiterbedakan.

Contohbagidistribusiiniadalahdistribusi Maxwell untukkecepatanmolekular. Distribusi Bose-Einstein dan Fermi-Dirac berlakuapabilapartikelitutakterbedakan (akibatefekkuantum) yang masing-masingnyaberlakuuntuk spin bulatdantengahan (dalamsatuan $\sim$ ). RadiasitermaldanpanasspesifikmematuhidistribusiBose-Einstein, sedangkanelektron di dalamlogamdansemikonduktorsertalubang (hole) mematuhifungsidistribusi Fermi-Dirac.

*widya.fis57@gmail.com 
AplikasiDistribusi

Maxwell-Boltzmann

\section{dalamMenentukanKecepatanMolekular}

Laju rata-rata sebuahmolekuldalamsuatusistem gas ideal bersuhu $\mathrm{T}$ adalahsebagaiberikut:

$$
\begin{gathered}
\frac{1}{2} m \bar{v}^{2}=\frac{3}{2} k T \\
\bar{v}=\sqrt{\frac{3 k T}{m}}
\end{gathered}
$$

DalamkonteksTeoriKinetikMolekular

Gas,

gas

berisisejumlahbesarpartikeldalamgerakcepat. Setiappartikelmemilikikecepatan yang

berbeda, dansetiaptumbukanantarapartikelperubahankecepatandaripartikel. Pemahamantent angsifat gas membutuhkanpemahamantentangdistribusikecepatanpartikel.

Dalamdistribusi Maxwell-Boltzmann molekul-molekuldalam gas ideal dapatdibedakandansetiapkeadaandapatdiisilebihdarisatumolekul.

Statistik Maxwell-Boltzmann:

$$
N_{j}=\frac{N}{Z} g_{j} \exp \left(-\frac{\varepsilon_{j}}{k T}\right)
$$

Jumlah rata-rata molekul yang energinyaantara $\varepsilon_{j}$ dan $\varepsilon_{j}+\Delta \varepsilon_{j}$

$$
\Delta N_{j}=\frac{N}{Z} \Delta g_{j} \exp \left(-\frac{\varepsilon_{j}}{k T}\right)
$$

Jumlahkeadaan yang energinyaantara $\varepsilon_{j}$ dan $\varepsilon_{j}+\Delta \varepsilon_{j}$

Persamaan1.....

$$
\Omega\left(\varepsilon_{j}\right)=\Delta g_{j}=\frac{d \Phi\left(\varepsilon_{j}\right)}{d \varepsilon} \Delta \varepsilon
$$

Tinjauansistempartikeldalamkotak 3-D:

$$
\begin{aligned}
& \Phi(\varepsilon)=\frac{1}{8} \text { volume bola }=\frac{1}{8} \frac{4}{3} \pi R^{3} \\
& \text { dengan } R^{2}=n_{j}^{2}=n_{x}^{2}+n_{y}^{2}+n_{z}^{2}
\end{aligned}
$$

Nyatakandalam $n_{j}$ :

Persamaan2....

$$
\Phi\left(n_{j}\right)=\frac{1}{8} \frac{4}{3} \pi n_{j}^{3}=\frac{\pi}{6} n_{j}^{3}
$$


Persamaan3.....

$$
\Omega\left(n_{j}\right)=\Delta g_{j}=\frac{d \Phi\left(n_{j}\right)}{d n_{j}}=\frac{\pi}{2} n_{j}^{2} \Delta n_{j}
$$

Pernyataanenergi $\varepsilon_{j}$ :

Persamaan4.....

$$
\varepsilon_{j}=\frac{\pi^{2} \hbar^{2}}{2 m L^{2}}\left(n_{x}^{2}+n_{y}^{2}+n_{z}^{2}\right)=\frac{h^{2}}{8 m} V^{-2 / 3} n_{j}^{2}
$$

FungsiPartisi Z:

$$
Z=\sum \Delta g_{j} \exp \left(-\frac{\varepsilon_{j}}{k T}\right)=\frac{\pi}{2} \sum_{j} n_{j}^{2} \Delta n_{j} \exp \left(-\frac{h^{2} V^{-2 / 3}}{8 m k T} n_{j}^{2}\right)
$$

Aproksimasi:

Persamaan5......

$$
Z=\frac{\pi}{2} \int_{0}^{\sim} n_{j}^{2} \exp \left(-\frac{h^{2} V^{-2 / 3}}{8 m k T} n_{j}^{2}\right) d n_{j=} V\left(\frac{2 \pi m k T}{h^{2}}\right)^{3 / 2}
$$

Sekarangkitanyatakanindeks

$\mathrm{n}$

padapersamaan-

persamaansebelumnyamenjadiindeks v (kecepatan):

PernyataanEnergi:

Persamaan6...........

$$
\varepsilon_{j}=\frac{h^{2}}{8 m} V^{-2 / 3} n_{j}^{2}=\frac{1}{2} m v_{j}^{2}
$$

Persamaan 6 ditambahdenganpersamaan 3 menjadi:

Persamaan7.....

$$
\Delta g_{v}=\frac{4 \pi m^{3} V}{h^{3}} v^{2} \Delta v
$$

Sehingga statistic Maxwell Boltzmann menjadi:

Persamaan8..........

$$
\Delta N_{v}=\frac{4 N}{\sqrt{\pi}}\left(\frac{m}{2 k T}\right)^{3 / 2} v^{2} \exp \left(-\frac{m v^{2}}{2 k T}\right) \Delta v
$$

Jumlah rata-rata molekul yang lajunyaantara $\mathrm{v}$ dan $\mathrm{v}+\Delta \mathrm{v}$ 
DistribusiKecepatanmolekul

$$
\Delta N_{v}=\frac{4 N}{\sqrt{\pi}}\left(\frac{m}{2 k T}\right)^{3 / 2} v^{2} \exp \left(-\frac{m v^{2}}{2 k T}\right) \Delta v
$$

Menjadi:

Persamaan9.....

$$
\frac{\Delta N_{v}}{\Delta v}=\frac{4 N}{\sqrt{\pi}}\left(\frac{m}{2 k T}\right)^{3 / 2} v^{2} \exp \left(-\frac{m v^{2}}{2 k T}\right)
$$

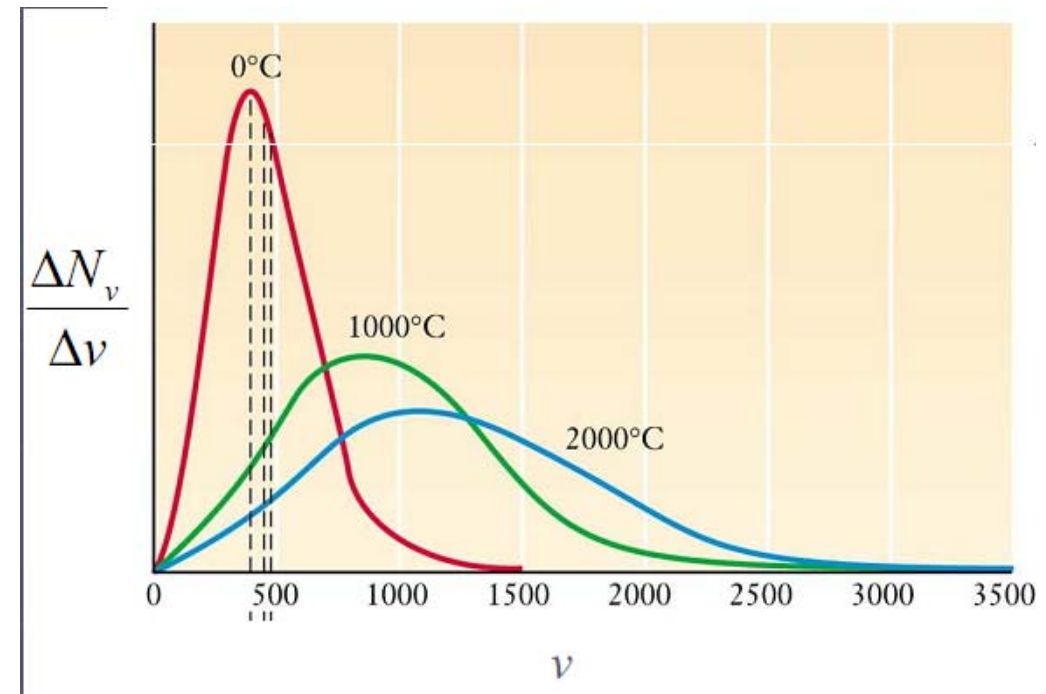

Grafik fungsi distribusi MB pada suhu berbeda

Lajudenganpeluangterbesarv $\mathrm{m}_{\mathrm{m}}$ :

$$
\begin{gathered}
\frac{d}{d v}\left(\frac{\Delta N_{v}}{\Delta v}\right)=0 \\
\frac{d}{d v}\left(\frac{4 N}{\sqrt{\pi}}\left(\frac{m}{2 k T}\right)^{3 / 2} v^{2} \exp \left(-\frac{m v^{2}}{2 k T}\right)\right)=0
\end{gathered}
$$

Persamaan10.....

$$
v_{m}=\sqrt{\frac{2 k T}{m}}
$$

Fungsidistribusi MB dinyatakandalamv $\mathrm{m}_{\mathrm{m}}$ :

Persamaan11........... 


$$
\frac{\Delta N_{v}}{\Delta v}=\frac{4 N}{\sqrt{\pi v_{m}^{3}}} v^{2} \exp \left(\frac{-v^{2}}{v_{m}^{2}}\right)
$$

Laju rata-rata molekul:

$$
\begin{gathered}
\bar{v}=\frac{1}{v} \sum v \Delta N \\
\bar{v}=\frac{4}{\sqrt{\pi v_{m}^{3}}} \int_{0}^{\sim} v^{3} \exp \left(\frac{-v^{2}}{v_{m}^{2}}\right) d v \\
\bar{v}=\frac{2}{\sqrt{\pi}} v_{m}=\sqrt{\frac{8 k T}{\pi m}}
\end{gathered}
$$

Distribusi root-mean-square $\left(\mathrm{v}_{\mathrm{rms}}\right)$ :

$$
\begin{gathered}
v_{r m s}=\sqrt{\overline{v^{2}}}=\left(\frac{1}{N} \sum v^{2} \Delta N_{v}\right)^{\frac{1}{2}}=\left[\frac{4}{\sqrt{\pi v_{m}^{3}}} \int_{0}^{\sim} v^{4} \exp \left(\frac{-v^{2}}{v_{m}^{2}}\right) d v\right] \\
v_{r m s}=\frac{3}{2} v_{m}=\sqrt{3 \frac{k T}{m}}
\end{gathered}
$$

Perbandinganketigajeniskelajuan:

$$
v_{m}: \bar{v}: v_{r m s}=\sqrt{\frac{2 k T}{m}}: \sqrt{\frac{8 k T}{\pi m}}: \sqrt{\frac{3 k T}{m}}=1: 1,128: 1,224
$$

\section{Visualisasiruangkecepatan}

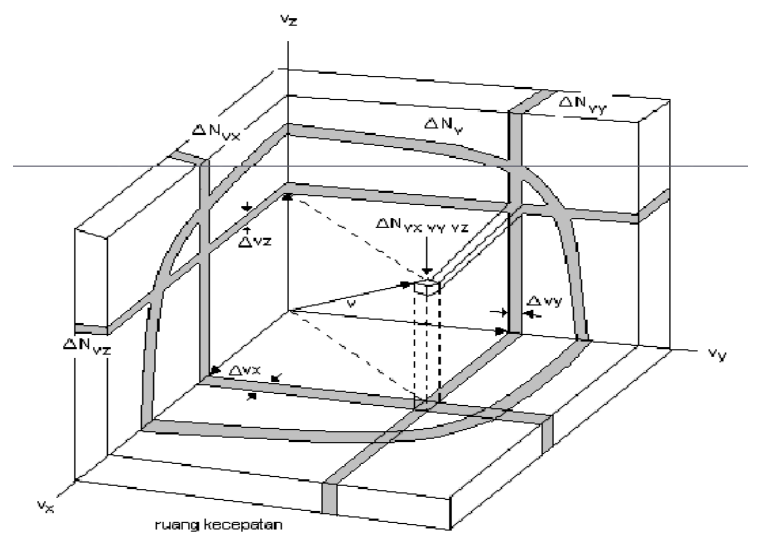

$\Delta \mathrm{N}_{\mathrm{v}}=$ jumlah vector kecepatan yang berujungpadakulit bola, yang kecepatannyaantara $\mathrm{v}$ dan $\mathrm{v}+\Delta \mathrm{v}$ volume kulitbola : $4 \pi \mathrm{v}^{2} \Delta \mathrm{v}$

Jumlahtitik representative tiapsatuanvolemedalamkulitataukerapatan $\rho_{\mathrm{v}}$ : 


$$
\rho_{v}=\frac{\Delta N_{v}}{4 \pi v^{2} \Delta v}=N\left(\frac{1}{\sqrt{\pi v_{m}}}\right)^{3} \exp \left(-\frac{v^{2}}{v_{m}^{2}}\right)
$$

Tinjauanelemenvolum $\Delta \mathrm{v}_{\mathrm{x}} \Delta \mathrm{v}_{\mathrm{y}} \Delta \mathrm{v}_{\mathrm{z}}$ dalamruangkecepatan

Jumlahtitik representative dalamelemen volume $\Delta \mathrm{v}_{\mathrm{x}} \Delta \mathrm{v}_{\mathrm{y}} \Delta \mathrm{v}_{\mathrm{z}}$ adalah $\Delta \mathrm{Nv}_{\mathrm{x}} \mathrm{v}_{\mathrm{y}} \mathrm{v}_{\mathrm{z}}$

Sehingga:

$$
\Delta N_{v_{x} v_{y} v_{z}}=\rho_{v} \Delta v_{x} \Delta v_{y} \Delta v_{z}
$$

Jumlahmolekul yang kecepatannyaantarav ${ }_{\mathrm{x}} \operatorname{danv}_{\mathrm{x}}+\Delta \mathrm{v}_{\mathrm{x}}, \mathrm{v}_{\mathrm{y}} \operatorname{danv}_{\mathrm{y}}+\Delta \mathrm{v}_{\mathrm{y}}, \mathrm{v}_{\mathrm{z}} \mathrm{danv}_{\mathrm{z}}+\Delta \mathrm{v}_{\mathrm{z}}$

$$
\Delta N_{v_{x} v_{y} v_{z}}=N\left(\frac{1}{\sqrt{\pi v_{m}}}\right)^{3} \exp \left[\frac{-\left(v_{x}^{2}+v_{y}^{2}+v_{z}^{2}\right)}{v_{m}^{2}}\right] \Delta v_{x} \Delta v_{y} \Delta v_{z}
$$

Kita tinjausalahsatukomponensaj, misalnyakomponen $\mathrm{x}$, makajumlahmolekul yang kecepatnnyaantarav $\operatorname{danv}_{\mathrm{x}}+\Delta \mathrm{v}_{\mathrm{x}}=\Delta \mathrm{NV}$

$$
\Delta N_{v_{x}}=N\left(\frac{1}{\sqrt{\pi v_{m}}}\right)^{3}\left[\int_{-\infty}^{\infty} \exp \left(\frac{-v_{y}^{2}}{v_{m}^{2}}\right) d v_{y} \int_{-\infty}^{\infty} \exp \left(\frac{-v_{z}^{2}}{v_{m}^{2}}\right) d v_{z}\right] \exp \left[\frac{-v_{x}^{2}}{v_{m}^{2}}\right] \Delta v_{x}
$$

Sehinggafungsidistribusikecepatan

Maxwell-

boltzmannuntuksatukomponenkecepatanadalah:

$$
\frac{\Delta N v_{x}}{\Delta v_{x}}=N \frac{1}{\sqrt{\pi v_{m}}} \exp \frac{-v_{x}^{2}}{v_{m}^{2}}
$$

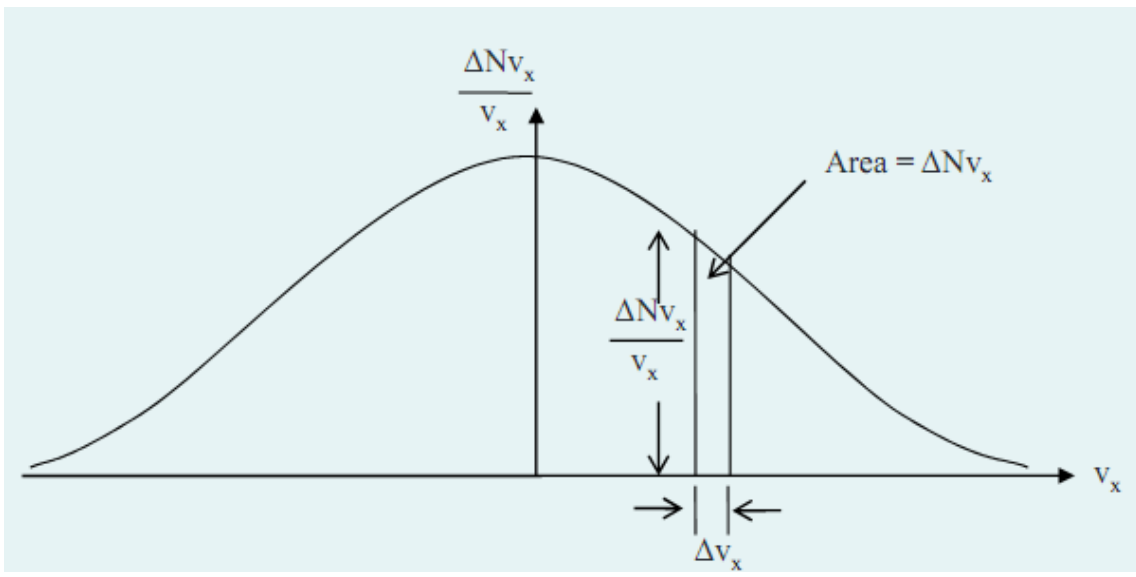

\section{Kecepatan Gas dalamTabung Gas}

The-Boltzmann Maxwell menggambarkan distribusi kecepatanpartikel digas, di manapartikeltidakterus-menerusberinteraksisatusama lain, tetapibergerakbebasantarapendek tabrakan . Inimenggambarkankemungkinanparti kelkecepatan (yang besardarivektorkecepatannya) yang dekatdengannilai yang 
diberikansebagai fungsidari suhu darisistem, massapartikel, danbahwanilaikecepatan.
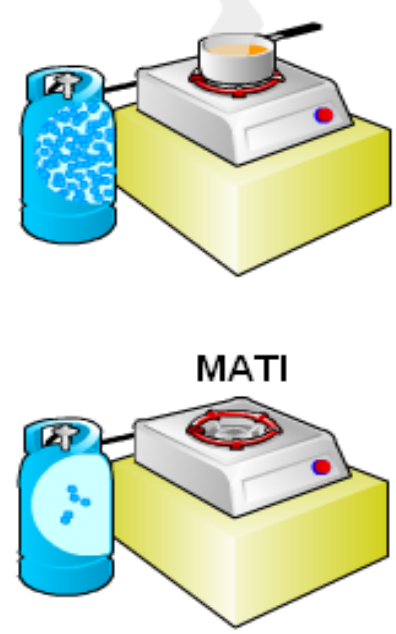

Dari gambardiatasdapatdilihatjikakompor gas sedangdihidupkanmakapartikel di dalamtabung gas bergeraklebihcepatdaripadasaatkompor gas dimatikan. Hal inidapatdiketahuibahwakuadratkecepatanpartikeldidalamtabung gas berbandingdengansuhupartikel gas.

\section{FenomenaLedakanTabung Gas}

Beberapawaktulalubanyakterjadiledakan yang disebabkankompor gas baikkarenabocormaupunsebab yang lainnya.dalamsebuahberita di kompasianasecara online du jelaskanbeberapapenyebabterjadinyaledakankompor gas.

Ada 3 sebabmengapakompor gas bisameledak, yang pertamakarenafaktoralat yang memangsudahtidaksesuaistandarataualatnyasudahAus, untukitupentingkiranyamemperhatikanumuralat, meskipunalattersebutstandartapikalausudahmelewatibataswaktupemakaiannyamak abisaberbahayajuga. Taruhlahselang, meskipun SNI tapikalautidakpernahdigantidandirawatmakabisabahayajuga. Sebagaigambaran, untukpemakaianselanghasilpembagiandarikonversi, 
itujangkawaktupenggunaannya paling lama 2 tahun, ataubisajuga 1 tahuntergantungintensitaspemakaiannya.

Faktor yang ke-duakarenaadanyaunsurkesalahandalampenggunaannya, inibisadiatasidenganmelakukansosialisasibagaimanamenggunakankompordenganb enar. Untukkomporhasilkonversiwaktuitukitasudahsertakan manual Book penggunaan, sertaadakelompok-kelompokmasyarakat yang turunkelapanganuntukmensosialisasikanpemakaiankompor yang benar.

Faktor yang ketigaadalahmasalahkriminaldanjustruinilah yang memakankorban paling banyak. Modusnyaituisitabung $3 \mathrm{~kg}$ disuntikketabung 12 kg, danitudilakukan di gudang di manaterdapatbanyaktumpukanElpiji.

Dalambanyakkasusledakanterjadipadasaatmenghidupkankompor gas, artinyapadakompor gas tersebutterjadiperubahansuhupadatabung gas, sehinggakecepatannya pun berubah. Jikaterjadikesalahanpadaselangataukebocorantabungmakakecepatanpartikel gas menumbukdindingtabungdalamtabung gas akansemakincepatsehingga atom-atom gas dalamtabungakanmendorongtutuptabung agar terbukaataumemecahkandindingtabung yang akhirnyamenimbulkansuaraledakan.

\section{Kesimpulan}

Aplikasi Distribusi Maxwell-Boltzman dapat diterapkan pada tabung gas untuk keperluan sehari-hari. Pada saat menyalakan kompor gas, yang berarti menaikkan suhu pada tabung gas, sehingga molekul gas di dalam tabung gas bergerak lebih cepat dari pada pada saat kompor gas dimatikan. Untuk itulah pengguna kompor gas disarankan untuk berhati-hati menyalakan kompor gas dan selalu memeriksa jika terdapat kebocoran pada tabung gas.

\section{DaftarRujukan}

AminuddinBama,

Akhmad. Jurnalfisika

FMIPA:

StatistikSistemZarah;dariklasikhinggaeksotik. UniversitasSriwijaya: 2009. http://jpsmipaunsri.files.wordpress.com//2010/08/0526-29-b-bama-ramlanganjil.pdfdiaksestanggal 30 desember 2010 
Anonim. AplikasiStatistik Maxwell-Boltzman, distribusiKecepatan. 2010.http://file.upi.edu/ai.php?dir=Direktori/D\%20-

\%20FPMIPA/JUR.\%20PEND.\%20FISIKA/ENDI\%20SUHENDI/Kuliah/ FI472\%20Fisika\%20Statistik/Bahan\%20Ajar/\&file=9.\%20Aplikasi\%20M B\%20distrib\%20kecepatan\%20[Compatibility\%20Mode].pdfdiaksestangg al 30 desember 2010

$\begin{array}{llll}\text { Anonym. } & 3 & \text { faktorpenyebabledakantabung } & 2010\end{array}$ http://regional.kompasiana.com/2010/07/07/3-faktor-penyebab-ledakankompor-gas/Diaksestanggal 30 desember 2010

Raharjo, Purwadi. Kecepatan atom gas dengandistribusi Maxwell-boltzmann. 2010. http://www.infometrik.com/wpcontent/uploads/2010/01/kecepatan_partikel_plasma_1.pdfdiaksestanggal 30 desember 2010 